\title{
Empirical Study on Economic Innovation and Development of Qinghai Biological Park
}

\author{
Liu Yafei ${ }^{1,}$,, Gan Shifen ${ }^{2}$, Ding Shengxi ${ }^{1}$ \\ ${ }^{1}$ Institute of Finance and Economics, Qinghai University, Xining, China \\ ${ }^{2}$ Kunlun College, Qinghai University, Xining, China \\ Email address: \\ 1240006179@qq.com (Liu Yafei), qhdxjjxdsx@126.com (Ding Shengxi) \\ ${ }^{*}$ Corresponding author
}

To cite this article:

Liu Yafei, Gan Shifen, Ding Shengxi. Empirical Study on Economic Innovation and Development of Qinghai Biological Park. Science Discovery. Vol. 7, No. 4, 2019, pp. 209-213. doi: 10.11648/j.sd.20190704.16

Received: July 13, 2019; Accepted: July 23, 2019; Published: July 29, 2019

\begin{abstract}
The park is a specific area for the agglomeration and development of related enterprises, a booster for speeding up the transformation of China's economic development mode, and an important support for achieving sustainable development. Based on the theory of Park Economic development, this paper investigates the overall economic development status, Park innovation, overall benefits of park enterprises and environmental protection of Qinghai bio-industrial park. The three-level evaluation index system of economic innovation and development in bio-parks was constructed, and the weight of each index and the comprehensive evaluation value of economic innovation and development in bio-parks were calculated by using the entropy method. The analysis finds that there are some problems in the economic innovation development of Qinghai Biological Park, such as the low scientific and technological content of some enterprises, lack of competitiveness; vague definition of government functions, excessive administrative intervention; inadequate infrastructure of the park; low production technology level, high energy consumption, and so on. Functions, strengthening the transformation of infrastructure, increasing the support of enterprises and other countermeasures to promote the economic innovation and development of bio-park.
\end{abstract}

Keywords: Park Economy, Innovative Development, Entropy Value Method

\section{青海生物园区经济创新发展实证研究}

刘亚菲 ${ }^{*}$, 甘世芬 ${ }^{2}$, 丁生喜 ${ }^{1}$

1 青海大学财经学院, 西宁, 中国

2青海大学昆仑学院, 西宁, 中国

\section{邮箱}

1240006179@qq.com (刘亚菲), qhdxjjxdsx@126.com (丁生喜)

摘要：园区是关联企业集聚发展的特定区域, 是加快我国经济发展方式转变的助推器, 也是实现可持续发展的重要 支撑。本文以园区经济发展理论为基础, 调查青海省生物产业园区经济发展的总体现状、园区创新情况、园区企业 总体效益情况和园区环保情况。构建生物园区经济创新发展三级评价指标体系，运用熵值法计算了各级指标的权重 和园区经济创新发展综合评价值。分析发现青海省生物园区经济创新发展存在部分入区企业科技含量偏低, 缺乏竞 争力; 政府职能界定模糊, 行政干预过多; 园区基础设施不够完善; 生产技术水平低, 能耗大等问题, 进而提出加 大科研技术投入力度、明确政府职能、加大基础设施改造力度、加大企业帮扶力度等对策来促进生物园区经济创新 发展。 
关键词: 园区经济, 创新发展, 熵值法

\section{1. 引言}

“园区经济”是指经济发展制度创新的一种模式。它是 通过一系列制度安排构筑一个在地理空间上相对集中的 企业或产业群体, 在与周边地区的产业经济联系经济空间 联系过程中带动区域经济发展的作用体。[1]20世纪八十年 代之后, 园区呈现了加速发展的趋势。引起了西方许多学 者对园区经济理论的研究和探索, 提出了园区发展的各种 理论, 主要包括技术创新理论、增长极理论、核心一边缘 扩散理论、三元参与理论和地区创造性理论。[2]国内对工 业园区研究的重点主要在产业结构升级、政策支持方向、 体制创新、土地规划调整等方面。[3]

青海省政府工作报告中强调力推园区经济优势互补、 竞相发展, 突出项目、融资、科技、体制等关键环节, 加 快打造几个重大产业基地。推动西宁经济技术开发区特色 化高端化发展, 提升辐射带动能力。目前, 对青海省园区 经济相关问题的研究十分缺乏, 因此, 对青海省园区经济 问题进行研究有重要的现实意义。

\section{2. 青海生物产业园区经济发展现状分析}

青海省自1992年开始先后建立了西宁经济技术开发 区、青海生物科技产业园、甘河工业区、格尔木昆仑经济 开发区等四个园区, 规划总面积 48.44 平方公里。[4]入驻 企业注册资金 28.33 亿元, 从业人员达 1.05 万人, 累计完成 固定资产投资 61 亿元，实现工业总产 48 亿元。

青海生物科技产业园(以下简称生物产业园)于2002年 4 月经省人民政府批准设立, 其发展定位是: 以青藏高原 独特的动植物资源为依托, 以功能配套的基础设施和良好 的服务环境为平台, 广泛吸引国内外投资者入驻园区, 重 点发展生物技术、中藏药加工。[5]

\section{1. 园区总体经济水平}

2010年园区生产总值39.8亿元，2016年增至102亿元， 增长率达到 $156 \%$; 工业总产值从 84.3 亿元增至 272 亿元, 工业增加值从 34.7 亿元增至 85 亿元, 园区固定资产投资从 30 亿元增至 73 亿元, 园区公益项目投资额从 15.7 亿元增至 59 亿元, 入驻企业数从 346 家增至 499 家, 其中中小型企业 数从 18 家增至 30 家, 园区从业人员从 8584 人增至 16080 人。

\section{2. 园区创新发展情况}

作为创新活动的集聚地, 青海生物园区自主创新能力不 断提升。2010年至2016年园区企业研发投入比例从1.3\%增至 $2.3 \%$, 园区各类领军人才从 2 人增至 13 人，园区实施高新技 术企业所得税减免政策, 科研公共服务平台从 3 家增至14家, 合作基地从 2 个增至 4 个, 形成了生物医药产业集群。

随着青海省生物园区的发展壮大, 取得了显著的效益。 企业每平方公里的收入从 2010 年的 9.87 亿元到2016年增
长到了 25.31 亿元, 万名人员当中拥有的专利发明数量从 108项增至 44 项，高新科技企业产品销售收入从5.8亿元增 值 16.4 亿元，高新科技企业出口产品额从 0.7 亿元增至 1.6 亿元, 高新技术产业工业增加值率从 $10 \%$ 增至 $33 \%$, 新兴 产业产值占工业产值比重从20\%增至35\%。

\section{3. 园区环保情况}

青海生物园区发展过程中, 逐步树立绿色发展理念[6], 重视园区环境保护。2010-2016年, 园区环保产业占GDP 的比重从 $8 \%$ 增至 $17 \%$, 增长比较显著。工业污水收集. 处 理比例从 $78 \%$ 增至 $88 \%$, 资源回收利用率从 $22 \%$ 增至 $30 \%$ 。 但是从园区万元产值能耗情况来看, 并不乐观, 2010 年万 元产值消耗标准煤 0.12 吨, 2016年则为 0.15 吨, 有所增加。 说明尽管园区环保产业在发展, 但是总体生产技术水平不 高, 能耗水平较高, 阻碍园区发展。

\section{3. 青海生物产业园区经济创新发展综合评价}

\section{1. 评价指标体系构建}

本文依据国家科技部发布的创新型园区建设指南, 参 照国内外园区评价指标, 对青海省生物园区经济发展的持 续性评价指标进行了构建。结合硅谷指数 [7]、中关村指数 [8]、张江指数等国内外评价指标, 对青海省生物园区经济 创新发展评价体系进行了设计, 主要从创新要素、创新基 础、产出效益和环保情况等四方面选择相关评价指标, 具 体见表1。

表1 青海省生物产业园区经济创新发展评价指标。

\begin{tabular}{|c|c|c|}
\hline 一级指标 & 二级指标 & 三级指标 \\
\hline \multirow{2}{*}{ 创新要素 } & 创新资金 & $\begin{array}{l}\text { 园区财政科技支出比例 } \mathrm{X}_{1} \\
\text { 企业研发投入比例 } \mathrm{X}_{2}\end{array}$ \\
\hline & 创新人才 & $\begin{array}{l}\text { 领军型人才 } \mathrm{X}_{3} \\
\text { 园区从业人员 }\end{array}$ \\
\hline \multirow{3}{*}{ 创新基础 } & 创新主体 & $\begin{array}{l}\text { 中小型企业的数量增长 } \mathrm{X}_{5} \\
\text { 园区工业增加值占园区GDP的比重 } \mathrm{X}_{6} \\
\text { 高新技术企业所得税减免政策 } \mathrm{X}_{7}\end{array}$ \\
\hline & 创新政策 & $\begin{array}{l}\text { 问新抆个企业所得棁成免政來 } X_{7} \\
\text { 产业集群 } \mathrm{X}_{8} \\
\text { 合作基地 } \mathrm{X}_{9}\end{array}$ \\
\hline & 创新平台 & $\begin{array}{l}\text { 科技公共服务平台 } \mathrm{X}_{10} \\
\text { 㽟化器 } \mathrm{X}_{11}\end{array}$ \\
\hline \multirow[b]{2}{*}{ 产出效益 } & 知识效益 & $\begin{array}{l}\text { 一万名人员当中拥有的专利发明数量 } \mathrm{X}_{12} \\
\text { 高新科技企业产品销售收入 } \mathrm{X}_{13}\end{array}$ \\
\hline & 物质效益 & $\begin{array}{l}\text { 高新科技企业出口产品金额 } \mathrm{X}_{14} \\
\text { 每平方公里收入(园区GDP/园区面积) } \mathrm{X}_{15} \\
\text { 高新技术产业工业增加值率 } \mathrm{X}_{16} \\
\text { 新兴产业产值占工业产值比重 } \mathrm{X}_{17}\end{array}$ \\
\hline \multirow{2}{*}{ 环保情况 } & 环保生产 & 园区万元增加值能耗 $\mathrm{X}_{18}$ \\
\hline & 环保管理 & $\begin{array}{l}\text { 环保产业占园区GDP的比重 } \mathrm{X}_{20} \\
\text { 资源回收利用效率 } \mathrm{X}_{21}\end{array}$ \\
\hline
\end{tabular}

(资料来源: 文中相关数据资料是作者从青海生物园区管委会调查, 并进 行整理得到)。 


\section{2. 青海省生物园区经济创新发展评价分析}

本研究采用熵值法, 其基本步骤如下:

一是原始数据的收集与整理; (通过到生物园区实地 调研获得, 相关原始数据略)

二是数据处理一标准化处理; (限于篇幅所限, 标准 化数据略)

三是计算指标信息熵值和信息效用价值;

四是计算评价指标权重。

以下是具体步骤:
首先对数据进行无量纲化处理, 公式为 $Y^{\prime}{ }^{\prime}=(X i j-X$ 均 值)/标准差, 由于该公式计算出来标准化值会对后面的计 算造成影响, 因此这里进行指标平移, 即 $Y i j=Y i j '+A$, 这里 $\mathrm{A}$ 取值为 2 。

(2)求第 $\mathrm{j}$ 项指标在第项方案中的比重

$$
P_{i j}=\frac{y_{i j}}{\sum_{i=1}^{k} y_{i j}}
$$

表2 Pij矩阵。

\begin{tabular}{|c|c|c|c|c|c|c|c|}
\hline & 2010年 & 2011年 & 2012年 & 2013年 & 2014年 & 2015年 & 2016年 \\
\hline $\mathrm{X}_{1}$ & 0.03476 & 0.08755 & 0.10515 & 0.14034 & 0.193135 & 0.210732143 & 0.228329286 \\
\hline $\mathrm{X}_{2}$ & 0.04505 & 0.08417 & 0.10373 & 0.14286 & 0.162418 & 0.221103413 & 0.240664828 \\
\hline $\mathrm{X}_{3}$ & 0.06983 & 0.06983 & 0.10391 & 0.12095 & 0.172069 & 0.206148571 & 0.257268571 \\
\hline $\mathrm{X}_{4}$ & 0.0533 & 0.09962 & 0.11029 & 0.11456 & 0.144443 & 0.224482143 & 0.253296429 \\
\hline $\mathrm{X}_{5}$ & 0.14407 & 0.15711 & 0.18972 & 0.19624 & 0.044944 & 0.045595682 & 0.222324841 \\
\hline $\mathrm{X}_{6}$ & 0.25118 & 0.10174 & 0.10098 & 0.10117 & 0.101168 & 0.100214928 & 0.243554112 \\
\hline $\mathrm{X}_{7}$ & 0.14286 & 0.14286 & 0.14286 & 0.14286 & 0.142857 & 0.142857143 & 0.142857143 \\
\hline $\mathrm{X}_{8}$ & 0.0665 & 0.0665 & 0.0665 & 0.20013 & 0.200127 & 0.200127143 & 0.200127143 \\
\hline $\mathrm{X}_{9}$ & 0.07143 & 0.07143 & 0.07143 & 0.14286 & 0.214286 & 0.214285714 & 0.214285714 \\
\hline $\mathrm{X}_{10}$ & 0.05192 & 0.08633 & 0.10353 & 0.12074 & 0.172349 & 0.223961589 & 0.241165172 \\
\hline $\mathrm{X}_{11}$ & 0.0574 & 0.0574 & 0.12387 & 0.1571 & 0.157101 & 0.190335714 & 0.256805714 \\
\hline $\mathrm{X}_{12}$ & 0.05583 & 0.08484 & 0.09209 & 0.12835 & 0.179119 & 0.215382143 & 0.244391429 \\
\hline $\mathrm{X}_{13}$ & 0.04969 & 0.0741 & 0.10375 & 0.13339 & 0.194422 & 0.210115714 & 0.234527857 \\
\hline $\mathrm{X}_{14}$ & 0.03113 & 0.07458 & 0.11803 & 0.16148 & 0.183204 & 0.20493 & 0.226655 \\
\hline $\mathrm{X}_{16}$ & 0.0354 & 0.08499 & 0.10979 & 0.13459 & 0.200721 & 0.208987143 & 0.22552 \\
\hline$X_{17}$ & 0.04183 & 0.07905 & 0.10386 & 0.14109 & 0.190714 & 0.215528571 & 0.227935714 \\
\hline $\mathrm{X}_{18}$ & 0.22305 & 0.22305 & 0.16692 & 0.05464 & 0.110779 & 0.166915714 & 0.054643571 \\
\hline $\mathrm{X}_{19}$ & 0.04279 & 0.06225 & 0.12062 & 0.15954 & 0.19845 & 0.178992857 & 0.237365 \\
\hline $\mathrm{X}_{20}$ & 0.00608 & 0.10182 & 0.1497 & 0.1497 & 0.197569 & 0.173632857 & 0.221505714 \\
\hline $\mathrm{X}_{21}$ & 0.02658 & 0.11078 & 0.11078 & 0.16692 & 0.138847 & 0.194983571 & 0.251119286 \\
\hline
\end{tabular}

(3)计算指标熵值

$$
\left.\mathrm{e}_{\mathrm{i}}=\mathrm{k} \sum_{\mathrm{i} 1}^{\mathrm{m}}\left(\mathrm{P}_{\mathrm{i}, \mathrm{j}} \times \ln \mathrm{P}_{\mathrm{ij}}\right) \text { (令 } \mathrm{k}=\frac{1}{\ln \mathrm{m}} \text {, 其中 } \mathrm{m} \text { 为 } 7\right)
$$

(4)计算差异性系数

$$
d_{i}=1-e_{i}
$$

式中, $d_{i}$ 表示第 $\mathrm{i}$ 个指标的信息熵冗余度

(5)计算指标权重

$$
w_{i}=\frac{d_{i}}{\sum_{j-1}^{n} d_{i}}
$$

表3 各指标权重计算表。

\begin{tabular}{llll}
\hline 指标 & $\mathbf{e}_{\mathbf{i}}$ & $\mathbf{d}_{\mathbf{i}}$ & 权重 \\
\hline $\mathrm{X}_{1}$ & 0.227221691 & 0.772778309 & 0.05511 \\
$\mathrm{X}_{2}$ & 0.27175148 & 0.72824852 & 0.05193 \\
$\mathrm{X}_{3}$ & 0.361673764 & 0.638326236 & 0.04552 \\
\hline
\end{tabular}




\begin{tabular}{|c|c|c|c|}
\hline 指标 & $\mathbf{e}_{\mathbf{i}}$ & $d_{i}$ & 权重 \\
\hline $\mathrm{X}_{4}$ & 0.304095608 & 0.695904392 & 0.04963 \\
\hline $\mathrm{X}_{5}$ & 0.543157713 & 0.456842287 & 0.03258 \\
\hline $\mathrm{X}_{6}$ & 0.675281462 & 0.324718538 & 0.02316 \\
\hline$X_{7}$ & 0.540938044 & 0.459061956 & 0.03274 \\
\hline $\mathrm{X}_{8}$ & 0.35074429 & 0.64925571 & 0.0463 \\
\hline $\mathrm{X}_{9}$ & 0.366812032 & 0.633187968 & 0.04515 \\
\hline$X_{10}$ & 0.298865115 & 0.701134885 & 0.05 \\
\hline$X_{11}$ & 0.319177228 & 0.680822772 & 0.04855 \\
\hline$X_{12}$ & 0.313464617 & 0.686535383 & 0.04896 \\
\hline$X_{13}$ & 0.290271093 & 0.709728907 & 0.05061 \\
\hline $\mathrm{X}_{14}$ & 0.210156949 & 0.789843051 & 0.05632 \\
\hline$X_{15}$ & 0.253372646 & 0.746627354 & 0.05324 \\
\hline $\mathrm{X}_{16}$ & 0.230128987 & 0.769871013 & 0.0549 \\
\hline$X_{17}$ & 0.258351823 & 0.741648177 & 0.05289 \\
\hline $\mathrm{X}_{18}$ & 0.651210236 & 0.348789764 & 0.02487 \\
\hline $\mathrm{X}_{19}$ & 0.262407116 & 0.737592884 & 0.0526 \\
\hline $\mathrm{X}_{20}$ & 0.060348513 & 0.939651487 & 0.06701 \\
\hline$X_{21}$ & 0.187602024 & 0.812397976 & 0.05793 \\
\hline
\end{tabular}

表4 各指标权重排序表。

\begin{tabular}{|c|c|}
\hline 指标排序 & 权重排序 \\
\hline 环保产业占园区GDP的比重 $\mathrm{X}_{20}$ & 0.067008034 \\
\hline 资源回收利用效率X & 0.057933385 \\
\hline 高新科技企业出口产品金额 $\mathrm{X}_{14}$ & 0.056324957 \\
\hline 园区财政科技支出比例 $X_{1}$ & 0.055108044 \\
\hline 高新技术产业工业增加值率 $\mathrm{X}_{16}$ & 0.05490072 \\
\hline 每平方公里收入 $X_{15}$ & 0.053243178 \\
\hline 新兴产业产值占工业产值比重 $X_{17}$ & 0.052888105 \\
\hline 工业污水收集处理比例 $X_{19}$ & 0.052598915 \\
\hline 企业研发投入比例 $\mathrm{X}_{2}$ & 0.051932554 \\
\hline 高新科技企业产品销售收入X $\mathrm{X}_{13}$ & 0.050611891 \\
\hline 科技公共服务平台 $\mathrm{X}_{10}$ & 0.049999038 \\
\hline 园区从业人员 $\mathrm{X}_{4}$ & 0.049626043 \\
\hline 一万名人员当中拥有的专利发明数量 $\mathrm{X}_{12}$ & 0.048957924 \\
\hline 孵化器 $\mathrm{X}_{11}$ & 0.048550549 \\
\hline 产业集群 $\mathrm{X}_{8}$ & 0.046299452 \\
\hline 领军型人才 $\mathrm{X}_{3}$ & 0.045520054 \\
\hline 合作基地 $\mathrm{X}_{9}$ & 0.045153636 \\
\hline 高新技术企业所得税减免政策 $\mathrm{X}_{7}$ & 0.032736434 \\
\hline 中小型企业的数量增长 $\mathrm{X}_{5}$ & 0.032578146 \\
\hline 园区万元增加值能耗 $X_{18}$ & 0.02487275 \\
\hline 园区工业增加值占园区GDP的比重 $\mathrm{X}_{6}$ & 0.023156193 \\
\hline
\end{tabular}

从表4可以看出环保产业占园区GDP的比重、资源回 收利用效率、高新科技企业出口产品金额、园区财政科技 支出比例、高新技术产业工业增加之率、每平方公里收入、 新兴产业产值占工业产值比重、工业污水收集处理比例、 企业研发投入比例和高新科技企业产品销售收入的权重 值都在 0.05 以上, 说明这些指标对青海省生物园区经济发 展有较大的贡献。但高新技术企业所得税减免政策、中小 型企业数量增长、园区万元增加值能耗和园区工业增加值 占园区GDP的比重的权重值都在 0.035 以下, 说明这些指 标对青海省生物园区经济发展的贡献较小, 需要加大这些 指标的投入。

\section{3. 青海省生物园区经济创新发展评价结果}

(1)计算评价值

$$
\mathrm{F} \sum_{j=1}^{m} \omega i={ }^{\prime} \mathrm{Yi}
$$

$\omega \mathrm{i}$ 代表权重, Yij是原始数据无量纲化后的值

表5 生物园区经济创新发展评价值。

\begin{tabular}{ll}
\hline 年份 & F评价值 \\
\hline 2010 & -1.15973 \\
2011 & -0.7448 \\
2012 & -0.42264 \\
2013 & 0.011958 \\
2014 & 0.41987 \\
2015 & 0.723484 \\
2016 & 1.171864 \\
\hline
\end{tabular}

(2)评级结果讨论

第一, 从表 5 熵值法计算综合得分值可以看出, 生物 园区经济发展水平持续上升, 从2000年的-1.15973上升至 2016年的1.171864。

第二, 从表4各指标权重排序表可以看出, 生物园区 近几年经济持续发展的主要动力是环保支出、科技支出、 
高新技术企业发展, 以及创新平台建设、创新人才等方面。 但是，在反映政策层面的高新技术企业所得税减免政策、 反映园区经济结构的园区工业增加值占园区GDP的比重、 反映生产技术水平的园区万元增加值能耗、以及反映园区 经济发展活力的中小型企业的数量增长等指标权重贡献 很小, 都在 0.03 以下, 说明这些是当前制约生物园区经济 持续发展的主要因素。从上表各指标的权重可以看出, 创 新投入、创新主体、企业绩效、环保生产是园区评价的关 键要素。

\section{4. 结论}

本文以2010-2016年青海省生物产业园区经济发展的总 体现状、园区创新情况、园区企业总体效益情况和园区环保 情况为基础, 构建生物园区经济创新发展三级评价指标体系, 进而展开实证研究, 针对存在的问题, 提出以下对策建议。

第一, 加大科研技术投入力度, 打造创新园区。组织 园区企业开展争创国家级高新技术企业、国家工程中心专 项活动, 对通过的企业给予重奖。支持企业加大对新药、 新食品营销推广, 对在省级以上电视媒体对国家新药、省 级名牌进行广告宣传的企业给予一定的补贴。改善留学科 技人员、科技骨干在园区的生活条件。

第二，明确政府职能，有效整合市场与政府的力量。政 府应提供以下服务: 在园区建设初期进行基础设施投资、建 设和管理，运用行政力量及信息优势，对园区的产业链网络 [9]进行统一规划和设计; 搭建信息交流平台, 引导企业入园 并在运营中适时引入新成员补链; 提供政策优惠吸引企业入 园，包括财政、税收、投资等方面; 监督约束污染行为, 即 通过实时监测手段监督园区内企业行为, 对污染环境的企业 予以坚决处罚, 并对园区最终废弃物进行管理等。

第三, 加大基础设施改造力度, 形成配套条件新格局。 生物园区需加大基础设施改造, 完善通信网络, 消灭网络 不畅死角。加大道路建设和老旧建筑的拆除、外墙美化。 在完善配套、提升服务水平的基础上，鼓励企业、社会公 办文化、学校、高档住宅区、餐饮、娱乐等休闲产业和现 代服务业, 促进园区商业繁荣。

第四, 加大企业帮扶力度, 促进企业做大做强。一是 大力支持企业上市, 根据企业上市工作需要, 要一事一议, 用特事特办的方式重点协调、解决好园区企业上市过程中 涉及的项目审批、土地出让、产权转让、财政税收政策及 社会保障等方面的问题; 二是要提高招商引资项目质量, 对引进项目的投入产出比、土地利用率、投资强度、财税 贡献度等几个关键参数设置硬指标, 进一步加大对生物、 医药企业的招商, 加强对新产业领域的研究, 创造园区新 的竞争优势、新的产业集群。[10]

\section{基金项目}

青海省科技计划项目(2019-ZJ-607)。

\section{参考文献}

[1] 刘傲洋. 我国园区经济发展问题探析 [J]. 青海社会科 学, 2004,(6):31-32。

[2] 李清源. 西方园区经济理论综述 [J]. 合作经济与科 技,2006,(5);43-45。

[3] 孙婧.中国工业园区的贸易与环境协调发展研究[D].青岛大 学, 2005。

[4] 苏海红, 德青措.依托园区构建青海特色城镇化发展研究 [J]. 青海社会科学,2013。

[5] 刘广明.西部欠发达地区基于工业园区的产业集群研究一 以青海省西宁市经济技术开发区为例 [D].南昌大学,2010。

[6] 秦瑞苗.中关村和硅谷比较研究一基于大学与科技园的合 作视角[D].中国集体经济,2016。

[7] 冯雪冬.中关村科技园区发展模式研究[D].首都经济贸易大 学, 2005。

[8] 郭静,乔琦,孙启宏,白璐.绿色发展, 循环发展.低碳发展与工 业园区的实践 $[\mathrm{J}]$.环境工程技术学报,2015。

[9] 甘树福.工业园区生态产业链设计研究[D].广东工业大 学, 2006 。

[10] 陆蓉.我国工业园区集群优势及集群发展研究 $[D]$.东华大 学, 2004。

\section{作者简介}

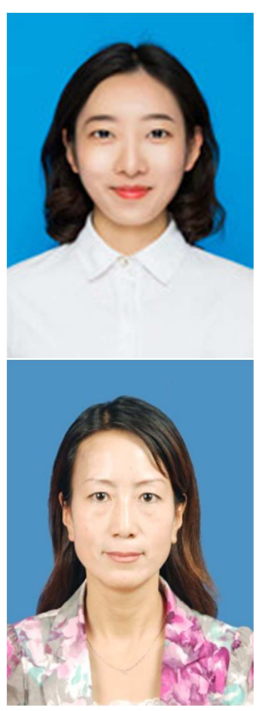

刘亚菲 (1996-), 女, 山东泰安人, 硕 士研究生, 研究方向为项目技术经济评 价。

丁生喜 (1971一), 女, 青海西宁人, 教 授, 硕士生导师, 研究方向为区域经济 发展与城镇化。 